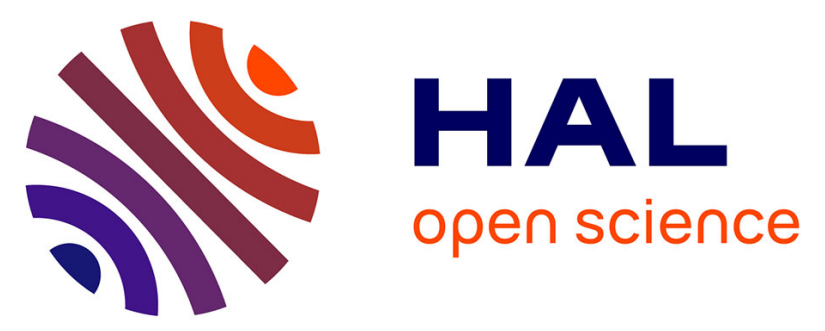

\title{
Impaired pulmonary function and its association with clinical outcomes, exercise capacity and quality of life in children with congenital heart disease
}

Hamouda Abassi, Arthur Gavotto, Marie Christine Picot, Héléna Bertet, Stefan Matecki, Sophie Guillaumont, Stephane Moniotte, Pascal Auquier, Johan Moreau, Pascal Amedro

\section{To cite this version:}

Hamouda Abassi, Arthur Gavotto, Marie Christine Picot, Héléna Bertet, Stefan Matecki, et al.. Impaired pulmonary function and its association with clinical outcomes, exercise capacity and quality of life in children with congenital heart disease. International Journal of Cardiology, 2019, 285, pp.86-92. 10.1016/j.ijcard.2019.02.069 . hal-02058708

\section{HAL Id: hal-02058708 https://hal.science/hal-02058708}

Submitted on 11 May 2020

HAL is a multi-disciplinary open access archive for the deposit and dissemination of scientific research documents, whether they are published or not. The documents may come from teaching and research institutions in France or abroad, or from public or private research centers.
L'archive ouverte pluridisciplinaire HAL, est destinée au dépôt et à la diffusion de documents scientifiques de niveau recherche, publiés ou non, émanant des établissements d'enseignement et de recherche français ou étrangers, des laboratoires publics ou privés. 


\title{
Impaired pulmonary function and its association with clinical outcomes, exercise capacity and quality of life in children with congenital heart disease
}

\author{
Hamouda Abassi ${ }^{\mathrm{a}, \mathrm{b}}$, Arthur Gavotto ${ }^{\mathrm{a}}$, Marie Christine Picot $^{\mathrm{c}}$, Helena Bertet ${ }^{\mathrm{c}}$, Stefan Matecki ${ }^{\mathrm{f}}$, \\ Sophie Guillaumont ${ }^{\mathrm{a}, \mathrm{d}}$, Stephane Moniotte ${ }^{\mathrm{e}}$, Pascal Auquier ${ }^{\mathrm{b}}$, Johan Moreau ${ }^{\mathrm{a}}$, Pascal Amedro ${ }^{\mathrm{a}, \mathrm{b}, \mathrm{f}, *}$ \\ ${ }^{a}$ Paediatric and Congenital Cardiology Department, M3C Regional Reference Centre, Montpellier University Hospital, Montpellier, France \\ ${ }^{\mathrm{b}}$ Center for Studies and Research on Health Services and Quality of Life, Aix-Marseille University, Marseille, France \\ c Epidemiology Department, Montpellier University Hospital, Clinical Investigation Centre, INSERM-CIC 1411, University of Montpellier, Montpellier, France \\ ${ }^{\mathrm{d}}$ Paediatric Cardiology and Rehabilitation Unit, St-Pierre Institute, Palavas-Les-Flots, France \\ e Paediatric and Congenital Cardiology Department, St-Luc University Hospital, Brussels, Belgium \\ ${ }^{\mathrm{f}}$ PhyMedExp, University of Montpellier, INSERM, CNRS, France
}

Keywords:

Children

Congenital heart disease

Lung

Pulmonary function

Spirometry

\section{A B S T R A C T}

Background: Impaired pulmonary function is an independent predictor of mortality in adult congenital heart disease (CHD), but has been scarcely studied in the paediatric CHD population.

Aims: To compare the pulmonary function of children with CHD to healthy controls, and evaluate its association with clinical outcomes, exercise capacity, and quality of life.

Methods: Cross-sectional multicentre study among 834 children (555 CHD and 279 control subjects) who underwent a complete spirometry and a cardiopulmonary exercise test (CPET). The 5th centile (Z-score = -1.64) was used to define the lower limit of normal. The association of clinical and CPET variables with spirometry was studied using a multivariate analysis. Children and their parents filled in the Kidscreen health-related quality of life questionnaire.

Results: Forced vital capacity (FVC) and forced expiratory volume in $1 \mathrm{~s}$ (FEV1) Z-scores values were lower in children with CHD than controls ( $-0.4 \pm 1.5$ vs. $0.4 \pm 1.3, P<0.001$ and $-0.5 \pm 1.4$ vs. $0.4 \pm 1.2, P<0.001$, respectively), without any obstructive airway disorder. Restrictive pattern was more frequent in CHD patients than in controls ( $20 \%$ vs. $4 \%, P<0.0001$ ). FVC Z-scores were predominantly impaired in complex CHD, such as heterotaxy $(-1.1 \pm 0.6)$, single ventricle $(-1.0 \pm 0.2)$, and complex anomalies of the ventricular outflow tracts $(-0.9 \pm$ 0.1 ). In multivariate analysis, FVC was associated with age, body mass index, peak oxygen uptake, genetic anomalies, the number of cardiac surgery and cardiac catheter procedures. FVC and FEV1 correlated with self and proxy-related quality of life scores.

Conclusion: These results suggest that pulmonary function should be monitored early in life, from childhood, in the CHD population.

Trial registration number: NCT01202916, post-results.

\section{Introduction}

With an incidence at birth of nearly $1 \%$, congenital heart diseases (CHD) stand as the leading cause of congenital anomalies, and one-third

is The authors take responsibility for all aspects of the reliability and freedom from bias of the data presented and their discussed interpretation.

访战 Acknowledgement of grant support: The study was supported by Montpellier University - Hospital Clinical Research Program (PHRC 8422).

* Corresponding author at: Paediatric and Congenital Cardiology Department, Arnaud De Villeneuve University Hospital, 371 Avenue du Doyen Giraud, 34295 Montpellier, France.

E-mail address: p-amedro@chu-montpellier.fr (P. Amedro). of this population will undergo cardiac surgery or interventional cardiac catheterization [1]. Recent advances in paediatric cardiology have transferred mortality related to CHD from childhood to adulthood [2].

However, quality of life in children with CHD remains affected, especially when considering their physical well-being [3-7]. Indeed, we recently showed that exercise capacity of children with CHD, as measured by the maximum oxygen uptake ( $\mathrm{VO} 2_{\max }$ ), correlated with their quality of life [8] and was significantly lower than that of healthy controls, with a mean overall $\mathrm{VO}_{\max }$ decline of nearly $2 \%$ per year [9]. Moreover, we found that muscular deconditioning affected three times more children with CHD than controls, even for simple heart defects [9]. As a result, children with CHD may suffer from an unpleasant 
feeling of exercise-induced dyspnoea, which directly alters their quality of life.

The existence of an impaired exercise capacity in CHD classically involves multifactorial mechanisms, such as heart failure, chronotropic insufficiency, desaturation, and muscular deconditioning [10,11]. Nevertheless, the feeling of dyspnoea in children with CHD may also result from the existence of an intrinsic ventilatory limitation. In the literature, the heart-lung interaction in children with CHD has been mainly highlighted by the usual complications related to cardiac surgery and intensive care [12-14]. However, in the current era, two-thirds of children with CHD will not need any cardiac surgery procedure, and the majority of the remaining children undergoing any invasive procedure (cardiac surgery and/or catheterization) will be considered as healed.

Yet, the evaluation of the lung function and its impact on physical activity and quality of life, in children with CHD, have been scarcely reported, and the existing sources present conflicting results $[12,15,16]$. In adults with CHD, impairment of lung function is an independent predictor of prognosis, with a reduced forced vital capacity (FVC) related to CHD complexity, surgical history, and mortality [17]. Similar extensive data are not available in the paediatric CHD population.

In the current perspective of promoting physical activity, slowing down the $\mathrm{VO}_{\max }$ decline and avoiding muscular deconditioning in children with CHD, it is necessary to identify any existing pulmonary function impairment, and whether or not it would represent an additional factor associated with exercise-induced dyspnoea and impaired quality of life, in the paediatric CHD population.

Therefore, this study aimed to compare the pulmonary function of a large cohort of children with CHD, to age and gender-matched controls, using, for the first time, the international spirometry reference Z-scores equations. We also intended to evaluate the association of the FVC with clinical and patient-related outcomes, in children with CHD.

\section{Methods}

\subsection{Study design and population}

This multicentre cross-sectional study was carried out from October 2009 to October 2015 in three paediatric cardiology tertiary care referral centres in Europe (centre 1: Montpellier University Hospital, France; centre 2: Saint-Pierre Institute Children Hospital, Palavas-Les-Flots, France; centre 3: Saint-Luc University Hospital, Brussels, Belgium).

Children aged 5 to 18 years old were recruited in one of the three participant paediatric functional laboratories, after a complete physical examination and before they underwent a cardio-pulmonary exercise test (CPET). Children with any of the following conditions were not eligible (e.g. contraindications for exercise test): fever, uncontrolled asthma, respiratory failure, acute myocarditis or pericarditis, uncontrolled arrhythmias causing symptoms or hemodynamic compromise, uncontrolled heart failure, acute pulmonary embolus or pulmonary infarction, and children with mental impairment leading to inability to cooperate.

The CHD group consisted of children with any CHD as defined by the anatomic and clinical classification (ACC-CHD) [18], referred by their paediatric cardiologist to the functional laboratory for a CPET. Patients with CHD were categorized into three severity classes, on the 32nd Bethesda classification: mild, moderate and severe heart defects [19]. The following clinical data were collected: gender, age, weight, height, body mass index (BMI), medical treatments, the number and type of cardiac surgical and catheter procedures, the presence of a pacemaker, and the existence of genetic anomalies (Down, DiGeorge, Noonan, and Williams syndromes). The following echocardiography data were collected: systemic ventricular ejection fraction and the presence of a right ventricle systolic hypertension (right ventricle systolic pressure greater than one-third of systemic systolic pressure).

The control group consisted of children referred to a paediatric cardiologist for a nonsevere functional symptom related to exercise (murmur, palpitation, chest pain, and dyspnoea) or for a medical sports certificate. These children needed to have a completely normal check-up, including physical examination, ECG, and echocardiography, before they could be classified in the control group. Children with any chronic disease, medical condition (cardiac, neurological, respiratory, muscular or renal), or medical treatment, and those requiring any further specialized medical consultation were not eligible.

\subsection{Ethics approval}

The study was conducted in compliance with the Good Clinical Practices protocol and Declaration of Helsinki principles. It belongs to a European research program dedicated to quality of life and exercise capacity in children with CHD. It was approved by Ethics Committees in France (South Mediterranean IV) and Belgium (UCL Medical School), and was registered on ClinicalTrials.gov (number NCT01202916, post-results). Informed consent was obtained from all parents or legal guardians.

\subsection{Paediatric laboratory functional tests: spirometry and CPET}

The three paediatric laboratories used the same technical devices (Oxycon Pro, Jaeger, Erich Jaeger GmbH, Hoechberg, Germany) and functional test procedures were harmonized before the study started.

In terms of pulmonary function tests, spirometry was performed before the exercise test, with a flow volume curve and measurement of the forced expiratory volume in $1 \mathrm{~s}$ (FEV1), the forced vital capacity (FVC), and the FEV1/FVC ratio (FEV1/FVC\%). Spirometry was repeated at least three times to ensure reproducibility, following the current guidelines in children [20,21]. Results were expressed as raw values, percent predict values from Zapletal et al. [22], and Z-scores from the spirometry reference equations [23]. The 5th centile ( $Z$-score $=-1.64$ ) was used to define the lower limit of normal, as recommended [23].

The 3 laboratories used the same CPET paediatric cycle ergometer protocol and a single investigator measured the values of $\mathrm{VO}_{\max }$ and ventilatory efficiency (VE/VCO2 slope), as detailed in our previous studies [9]. As the $\mathrm{VO}_{\max }$ usually does not reach a plateau in children, the peak VO2 was informed.

\subsection{Quality of life assessment}

On the same day, children and their parents or legal guardians were offered to fill in the Kidscreen quality of life questionnaire, in a separate room. A specialist nurse supervised children and provided assistance, when necessary. The Kidscreen is a generic paediatric healthrelated quality of life instrument, validated for healthy and sick children ( 8 to 18 years old) and available in many European countries, including France and Belgium [24,25].

The Kidscreen-52 self-questionnaire (for children) measures 10 dimensions: physical well-being (5 items), psychological well-being ( 6 items), moods and emotions ( 7 items), self-perception ( 5 items), autonomy ( 5 items), parent relations and home life ( 6 items), social support \& peers ( 6 items), school environment ( 6 items), social acceptance (bullying) (3 items), and financial resources ( 3 items) [25].

The Kidscreen-27 proxy-questionnaire (for parents or legal guardians) measures 5 dimensions: physical well-being ( 5 items), psychological well-being ( 7 items), autonomy and parent relations ( 7 items), social support and peers ( 4 items), and school environment (4 items) [24].

\subsection{Statistical analysis}

The study population was described using mean values \pm standard deviations (SD) for quantitative variables and with frequencies for qualitative variables. Functional tests results (except for Z-scores) were described with means adjusted on gender and age \pm standard error of the mean (SEM). The continuous variable distributions were tested using the Shapiro-Wilk test. Quantitative variables were compared using the Student's $t$ test when the distribution was Gaussian and the Mann-Whitney test, otherwise. For qualitative variables, groups were compared using the $\chi^{2}$ test or Fisher's exact test.

Logistic models were used to identify the factors associated with an impaired FVC (e.g. Z-scores $<-1.64$ ) [23].

For each type of CHD, age and gender-matched control comparisons were performed. For a given CHD case, all the controls with the same gender and age (exact year of age) were used. The case with his (or her) matched-controls was considered as a cluster. Therefore mixed models were performed in which the clusters were introduced as a random effect.

A multiple linear regression was used to identify the explanatory factors for FVC (in Zscores) among children with CHD (all types of CHD combined). The clinically relevant variables with a $P$ value $\leq 0.2$ in the univariate analysis were included in the model. The final model was obtained using a backward selection with an exit threshold of 0.10 . The normality of residues in the final model was tested using the Shapiro-Wilk test.

Correlations between quality of life and raw spirometry results were performed using Pearson's or Spearman's coefficients, depending on the distribution of variables.

The statistical significance was set at 0.05 and analyses were performed using Statistical Analysis Systems version 9 (SAS Institute, Cary, NC, USA).

\section{Results}

\subsection{Population}

Over the study period, 2041 children underwent both a spirometry and a CPET in the three paediatric laboratories (centre 1: $n=872$; centre $2: n=1093$; centre $3: n=76$ ).

A total of 834 children were included in the study, 555 in the CHD group and 279 in the control group. In the CHD group, 158 families accepted to participate in the quality of life study and filled in the self and proxy questionnaires. The flow chart was presented on Supplementary Fig. 1. 
Table 1

Main demographic and functional tests data: comparison between CHD and controls.

\begin{tabular}{|c|c|c|c|}
\hline & CHD & Controls & $P$-value \\
\hline$N$ & 555 & 279 & \\
\hline Age (years) & $12.2 \pm 3.3$ & $11.1 \pm 2.6$ & $<0.0001$ \\
\hline Height $(\mathrm{cm})$ & $150.9 \pm 17.2$ & $149.4 \pm 15.8$ & 0.18 \\
\hline Weight (kg) & $44.0 \pm 15.7$ & $41.9 \pm 3.2$ & 0.15 \\
\hline BMI $\left(\mathrm{kg} / \mathrm{m}^{2}\right)$ & $18.7 \pm 3.6$ & $18.3 \pm 2.9$ & 0.32 \\
\hline Sex ratio (male/female) & 1.4 & 1.3 & 0.56 \\
\hline FVC (L) & $2.77 \pm 0.03$ & $3.17 \pm 0.04$ & $<0.0001$ \\
\hline$\%$ predicted FVC & $95.5 \pm 0.8$ & $104.5 \pm 1.1$ & $<0.0001$ \\
\hline Z-score FVC & $-0.4 \pm 1.5$ & $0.4 \pm 1.3$ & $<0.0001$ \\
\hline FEV1 (L) & $2.37 \pm 0.02$ & $2.73 \pm 0.03$ & $<0.0001$ \\
\hline$\%$ predicted FEV1 & $97.3 \pm 0.7$ & $106.7 \pm 1.0$ & $<0.0001$ \\
\hline Z-score FEV1 & $-0.5 \pm 1.4$ & $0.4 \pm 1.2$ & $<0.0001$ \\
\hline FEV1/FVC (\%) & $86.8 \pm 0.4$ & $86.8 \pm 0.5$ & 0.99 \\
\hline$\%$ predicted FEV1/FVC & $102.5 \pm 0.5$ & $102.7 \pm 0.6$ & 0.85 \\
\hline Z-score FEV1/FVC & $0.001 \pm 1.4$ & $0.014 \pm 1.2$ & 0.68 \\
\hline Peak VO2 (mL/kg/min) & $37.8 \pm 0.3$ & $42.5 \pm 0.4$ & $<0.0001$ \\
\hline$\%$ predicted $\mathrm{VO}_{\max }$ & $94.0 \pm 0.8$ & $105.9 \pm 1.1$ & $<0.0001$ \\
\hline $\mathrm{VE} / \mathrm{VCO}_{2}$ slope & $31.6 \pm 0.2$ & $29.3 \pm 0.3$ & $<0.0001$ \\
\hline
\end{tabular}

Legend: BMI, body mass index; CHD, congenital heart disease; FEV1, forced expiratory volume in $1 \mathrm{~s}$; FVC, forced vital capacity; FEV1/FVC, Tiffeneau index. VAT, ventilatory anaerobic threshold; VE/VCO2 slope, the minute ventilation/carbon dioxide production slope; $\mathrm{VO} 2_{\text {max }}$, maximum oxygen uptake. Values are mean \pm standard deviation or mean adjusted \pm SEM (for functional tests results except for Z-scores).

Regarding demographic data (Table 1 ), both groups were similar in terms of gender, weight and height. The control group was slightly younger than the CHD group $(11.1 \pm 2.6$ years vs. $12.2 \pm 3.3$ years, $P$ $<0.0001$, respectively). Similarly, we found no demographic differences between the three centres, except for moderately older children in the centre 3 ( $12.5 \pm 3.1$ years), than in centre $2(12.0 \pm 3.2$ years $)$ and centre $1(11.3 \pm 2.9$ years, $P=0.01)$.

The anomalies of the ventricular outflow tracts represented the most frequent CHD sub-group ( $n=299,53.0 \%$ ). In greater detail, the most frequent types of CHD were in the following order: coarctation of the aorta $(n=69,12.4 \%)$, tetralogy of Fallot $(n=66,11.9 \%)$, ventricular septal defect (VSD) ( $n=50,9 \%)$. The smallest samples were congenital anomalies of coronary arteries $(n=7)$, complex anomalies of atrioventricular connections $(n=6)$ and heterotaxy $(n=3)$. The CHD subgroups characteristics were detailed in Supplementary Table 1 (demographic and clinical data).

\subsection{Paediatric laboratory functional tests: global spirometry and CPET results}

The overall functional tests results were reported in Table 1. The FVC and the FEV1 in the CHD group were significantly lower than in the control group, as expressed in raw values, percent predicts, and Z-scores. However, the FEV1/FVC was similar in both groups, regardless of how values were expressed.

A total of 111 children with CHD had an impaired FVC (e.g. Z score $<$ $-1.64)$, which represented a significantly higher proportion than in the control group (20\% vs. $4 \%, P<0.0001$, respectively).

The spirometry reports in CHD sub-groups versus matched controls were detailed in Table 2. The FVC was lower in each CHD sub-group, except for patients with complex anomalies of atrioventricular connection (absence of statistically significant difference in this small sample of patients). In greater detail, the FVC was most impaired in the following CHD sub-groups: heterotaxy, functionally univentricular heart (e.g. single ventricle), and complex anomalies of the ventricular outflow tracts (e.g. tetralogy of Fallot, truncus arteriosus, pulmonary atresia, and double outlet right ventricle).

The FEV1 was lower in all CHD sub-groups than in controls, except for patients with heterotaxy, anomalies of the venous return and complex anomalies of atrioventricular connections. The FEV1 was most impaired in patients with functionally univentricular heart and complex anomalies of the ventricular outflow tracts.

The FEV1/FVC in each CHD sub-group was not significantly different from controls.

The exercise capacity in the CHD group was good, with a mean age and gender-adjusted peak VO2 of $37.8 \pm 0.3 \mathrm{~mL} / \mathrm{kg} / \mathrm{min}(94 \%$ of

Table 2

Pulmonary function in children with CHD population versus healthy controls.

\begin{tabular}{|c|c|c|c|c|c|c|c|c|c|c|}
\hline \multirow[t]{2}{*}{ Gender } & \multirow[t]{2}{*}{$\mathrm{N}_{\mathrm{CHD}} / \mathrm{N}_{\text {Controls }}$} & \multicolumn{3}{|l|}{$\begin{array}{l}\text { Z-score FVC } \\
\text { Mean } \pm \text { SD }\end{array}$} & \multicolumn{3}{|l|}{$\begin{array}{l}\text { Z-score FEV1 } \\
\text { Mean } \pm \text { SD }\end{array}$} & \multicolumn{3}{|c|}{$\begin{array}{l}\text { Z-score FEV1/FVC } \\
\text { Mean } \pm \text { SD }\end{array}$} \\
\hline & & CHD & Controls & $P$-value & CHD & Controls & $P$-value & CHD & Controls & $P$-value \\
\hline Male & $326 / 158$ & $-0.4 \pm 1.5$ & $0.5 \pm 1.3$ & $<0.001$ & $-0.4 \pm 1.4$ & $0.6 \pm 1.1$ & $<0.001$ & $0.1 \pm 1.5$ & $0.2 \pm 1.2$ & 0.88 \\
\hline Female & $229 / 121$ & $-0.5 \pm 1.6$ & $0.2 \pm 1.2$ & $<0.001$ & $-0.6 \pm 1.5$ & $0.1 \pm 1.2$ & $<0.001$ & $-0.1 \pm 1.4$ & $-0.2 \pm 1.2$ & 0.46 \\
\hline \multirow[t]{2}{*}{ ACC-CHD group } & \multirow[t]{2}{*}{$\mathrm{N}_{\mathrm{CHD}} / \mathrm{N}_{\text {Controls }}$} & \multicolumn{3}{|l|}{$\begin{array}{l}\text { Z-score FVC } \\
\text { Mean } \pm \text { SD }\end{array}$} & \multicolumn{3}{|l|}{$\begin{array}{l}\text { Z-score FEV1 } \\
\text { Mean } \pm \text { SD }\end{array}$} & \multicolumn{3}{|c|}{$\begin{array}{l}\text { Z-score FEV1/FVC } \\
\text { Mean } \pm \text { SD }\end{array}$} \\
\hline & & CHD & Controls & $P$-value ${ }^{\mathrm{a}}$ & CHD & Controls & $P$-value ${ }^{a}$ & CHD & Controls & $P$-value ${ }^{a}$ \\
\hline 1. Heterotaxy & $3 / 34$ & $-1.1 \pm 0.6$ & $0.3 \pm 1.0$ & 0.02 & $-0.7 \pm 0.6$ & $0.1 \pm 0.2$ & 0.17 & $1.0 \pm 0.7$ & $-0.2 \pm 0.2$ & 0.10 \\
\hline 2. Anomalies of the venous return & $14 / 149$ & $-0.3 \pm 0.4$ & $0.4 \pm 0.2$ & 0.03 & $-0.3 \pm 0.3$ & $0.4 \pm 0.2$ & 0.06 & $0.1 \pm 0.3$ & $0.1 \pm 0.1$ & 0.87 \\
\hline $\begin{array}{l}\text { 3. Anomalies of the atria and } \\
\text { interatrial communications }\end{array}$ & $32 / 199$ & $-0.3 \pm 0.2$ & $0.4 \pm 0.1$ & 0.01 & $-0.3 \pm 0.2$ & $0.3 \pm 0.1$ & 0.01 & $0.1 \pm 0.2$ & $-0.04 \pm 0.1$ & 0.54 \\
\hline $\begin{array}{l}\text { 4. Anomalies of the atrioventricular } \\
\text { junctions and valves }\end{array}$ & $28 / 167$ & $-0.6 \pm 0.3$ & $0.6 \pm 0.1$ & 0.0001 & $-0.8 \pm 0.2$ & $0.4 \pm 0.1$ & $<0.0001$ & $-0.2 \pm 0.2$ & $-0.1 \pm 0.1$ & 0.53 \\
\hline $\begin{array}{l}\text { 5. Complex anomalies of atrioventricular } \\
\text { connections }\end{array}$ & $6 / 58$ & $-0.5 \pm 0.5$ & $0.4 \pm 0.2$ & 0.09 & $-0.6 \pm 0.4$ & $0.2 \pm 0.1$ & 0.06 & $0.02 \pm 0.5$ & $-0.2 \pm 0.2$ & 0.72 \\
\hline 6. Functionally univentricular hearts & $36 / 208$ & $-1.0 \pm 0.2$ & $0.5 \pm 0.1$ & $<0.0001$ & $-1.2 \pm 0.2$ & $0.4 \pm 0.1$ & $<0.0001$ & $-0.1 \pm 0.2$ & $0.02 \pm 0.1$ & 0.75 \\
\hline 7. Ventricular septal defects & $50 / 236$ & $-0.3 \pm 0.2$ & $0.4 \pm 0.1$ & 0.0004 & $-0.4 \pm 0.2$ & $0.4 \pm 0.1$ & $<0.0001$ & $-0.1 \pm 0.2$ & $0.01 \pm 0.1$ & 0.49 \\
\hline 8.1 Transposition of the great arteries & $75 / 244$ & $-0.02 \pm 0.2$ & $0.5 \pm 0.1$ & 0.007 & $-0.1 \pm 0.1$ & $0.4 \pm 0.1$ & 0.001 & $0.1 \pm 0.1$ & $0.05 \pm 0.1$ & 0.84 \\
\hline $\begin{array}{l}\text { 8.2 Complex anomalies of the ventricular } \\
\text { outflow tracts }{ }^{\mathrm{b}}\end{array}$ & $117 / 276$ & $-0.9 \pm 0.1$ & $0.4 \pm 0.1$ & $<0.0001$ & $-1.1 \pm 0.1$ & $0.4 \pm 0.1$ & $<0.0001$ & $-0.1 \pm 0.1$ & $0.1 \pm 0.05$ & 0.23 \\
\hline 8.5 Aortic valve stenosis. Shone syndrome & $60 / 262$ & $-0.01 \pm 0.2$ & $0.4 \pm 0.1$ & 0.02 & $-0.1 \pm 0.1$ & $0.4 \pm 0.1$ & 0.006 & $0.05 \pm 0.2$ & $0.04 \pm 0.1$ & 0.99 \\
\hline 8.6 Pulmonary valve stenosis & $45 / 260$ & $-0.1 \pm 0.2$ & $0.4 \pm 0.1$ & 0.02 & $-0.2 \pm 0.2$ & $0.4 \pm 0.1$ & 0.001 & $-0.04 \pm 0.2$ & $0.05 \pm 0.1$ & 0.67 \\
\hline $\begin{array}{l}\text { 9. Anomalies of the extrapericardial } \\
\text { arterial trunks }\end{array}$ & $80 / 266$ & $-0.3 \pm 0.1$ & $0.4 \pm 0.1$ & $<0.0001$ & $-0.3 \pm 0.1$ & $0.4 \pm 0.1$ & $<0.0001$ & $0.1 \pm 0.1$ & $0.01 \pm 0.1$ & 0.54 \\
\hline $\begin{array}{l}\text { 10. Congenital anomalies of the } \\
\text { coronary arteries }\end{array}$ & $7 / 85$ & $-0.4 \pm 0.5$ & $0.5 \pm 0.2$ & 0.05 & $-0.8 \pm 0.5$ & $0.5 \pm 0.2$ & 0.005 & $-0.3 \pm 0.5$ & $0.05 \pm 0.1$ & 0.49 \\
\hline
\end{tabular}


predicted $\mathrm{VO} 2_{\max }$ ), but remained significantly lower than in matched controls. The ventilatory efficiency in the CHD group was moderately impaired, with a mean age and gender-adjusted VE/VCO2 slope of $31.6 \pm 0.2$, which was significantly higher than in matched controls (Table 1).

\subsection{Factors associated with an impaired FVC (Z-score $<-1.64)$}

The factors most associated with an impaired FVC were the existence of a CHD, the type of CHD sub-group, and the number of cardiac surgery procedures (Supplementary Table 2 ). In greater detail, the presence of a non-operated CHD increased the risk of presenting an impaired FVC by 2.9 , compared to controls $(P=0.01)$. In comparison with controls, CHD patients with a history of one cardiac surgery had a 5.4-fold increased risk of presenting an impaired FVC $(P<0.0001)$, and those with 2 or more cardiac surgeries had a 12.9-fold increased risk of presenting an impaired FVC $(P<0.0001)$. The FVC was not statistically different in terms of cardiac surgery operative approach (thoracotomy vs. median sternotomy). The CHD groups most associated with FVC impairment were the complex CHD, such as functionally univentricular heart and complex anomalies of the ventricular outflow tracts.

\subsection{Clinical determinants of FVC in the CHD group}

The FVC was associated with the age, the BMI, the level of peak VO2, the existence of genetic anomalies, the number of cardiac surgery and cardiac catheter procedures, in both univariate and multivariate analysis (Table 3 ). The final multivariate model explained $17 \%$ of the variability of FVC in the CHD group. The CHD severity associated with the FVC only in univariate analysis $(P=0.03)$. There was a trend for an association between FVC and increased VE/VCO2 slope $(P=0.05)$ or right ventricle hypertension $(P=0.05)$.

The FVC was not impacted by the age of the patient at first cardiac surgery procedure: the FVC was similar in children who underwent cardiac surgery in their first year of life, and in those who had a later surgical procedure (Z-score $=-0.57 \pm 1.5$ vs. $-0.66 \pm 1.3, P=0.6$, respectively).

3.5. Correlations between spirometry variables and quality of life scores in the CHD group

Self-reported quality of life scores ranged from $45.3 \pm 9.9$ in the physical well-being dimension to $53.1 \pm 10.6$ in the moods and emotions dimension. Proxy-reported quality of life scores ranged from $43.3 \pm 12.1$ in the social support and peers dimension to $50.2 \pm 10.7$ in the psychological well-being dimension (Fig. 1).

Table 3

FVC explanatory variables in the CHD group.

\begin{tabular}{|c|c|c|c|c|c|c|}
\hline \multirow{2}{*}{\multicolumn{3}{|c|}{ Variables }} & \multirow[t]{2}{*}{$N$} & \multirow[t]{2}{*}{$r$} & \multirow{2}{*}{$\begin{array}{l}\begin{array}{l}\text { Univariate } \\
\text { analysis }\end{array} \\
P \text {-value }\end{array}$} & \multirow{2}{*}{$\begin{array}{l}\text { Multivariate } \\
\text { analysis }(N=392) \\
P \text {-value }\end{array}$} \\
\hline & & & & & & \\
\hline \multicolumn{3}{|l|}{ Age (years) } & 553 & -0.07 & 0.08 & 0.02 \\
\hline \multicolumn{3}{|l|}{ BMI $\left(\mathrm{kg} / \mathrm{m}^{2}\right)$} & 553 & 0.23 & $<0.0001$ & $<0.0001$ \\
\hline \multicolumn{3}{|l|}{ VE/VCO2 slope } & 468 & -0.08 & 0.05 & - \\
\hline \multicolumn{3}{|c|}{ Percentage of predicted $\mathrm{VO}_{\max }$} & 553 & 0.13 & 0.002 & 0.0001 \\
\hline \multicolumn{3}{|l|}{ Variables } & $N$ & $\begin{array}{l}\text { Mean } \pm \text { SD } \\
(\text { Z-score FVC) }\end{array}$ & $P$-value & $P$-value \\
\hline \multirow{2}{*}{\multicolumn{2}{|c|}{ Gender }} & Girls & 227 & $-0.47 \pm 1.47$ & 0.53 & - \\
\hline & & Boys & 326 & $-0.39 \pm 1.53$ & & \\
\hline \multirow{3}{*}{\multicolumn{2}{|c|}{ CHD severity }} & Mild & 195 & $-0.19 \pm 1.41$ & 0.03 & - \\
\hline & & Moderate & 194 & $-0.54 \pm 1.43$ & & \\
\hline & & Severe & 164 & $-0.56 \pm 1.66$ & & \\
\hline \multirow{3}{*}{\multicolumn{2}{|c|}{ Number of cardiac surgical procedures }} & 0 & 152 & $0.002 \pm 1.41$ & $<0.0001$ & 0.003 \\
\hline & & 1 & 270 & $-0.48 \pm 1.38$ & & \\
\hline & & $\geq 2$ & 131 & $-0.80 \pm 1.72$ & & \\
\hline \multirow{2}{*}{\multicolumn{2}{|c|}{ Cardiac surgery operative approach }} & Thoracotomy & 33 & $-0.50 \pm 1.38$ & 0.38 & - \\
\hline & & Sternotomy & 237 & $-0.29 \pm 1.26$ & & \\
\hline \multirow{3}{*}{\multicolumn{2}{|c|}{ Number of cardiac catheter procedures }} & 0 & 388 & $-0.49 \pm 1.48$ & 0.20 & 0.09 \\
\hline & & 1 & 124 & $-0.21 \pm 1.49$ & & - \\
\hline & & $\geq 2$ & 41 & $-0.46 \pm 1.73$ & & \\
\hline \multirow{2}{*}{\multicolumn{2}{|c|}{ Altered systemic ventricle ejection fraction }} & No & 382 & $-0.41 \pm 1.43$ & 0.15 & - \\
\hline & & Yes & 12 & $-1.01 \pm 1.45$ & & \\
\hline \multirow{2}{*}{\multicolumn{2}{|c|}{ Right ventricle systolic hypertension }} & No & 334 & $-0.37 \pm 1.39$ & 0.05 & - \\
\hline & & Yes & 62 & $-0.76 \pm 1.59$ & & \\
\hline \multirow{12}{*}{$\begin{array}{l}\text { Cardiac } \\
\text { medications }\end{array}$} & ACE inhibitor or ARB & No & 537 & $-0.41 \pm 1.49$ & 0.12 & - \\
\hline & & Yes & 16 & $-1.00 \pm 1.67$ & & \\
\hline & Antiarrhythmic drug & No & 546 & $-0.41 \pm-1.50$ & 0.12 & - \\
\hline & & Yes & 7 & $-1.31 \pm 1.18$ & & \\
\hline & Beta blocker & No & 519 & $-0.42 \pm 1.49$ & 0.99 & - \\
\hline & & Yes & 34 & $-0.42 \pm 1.63$ & & \\
\hline & Calcium channel blockers & No & 549 & $-0.42 \pm 1.51$ & 0.65 & - \\
\hline & & Yes & 4 & $-0.76 \pm 0.54$ & & \\
\hline & Diuretics & No & 548 & $-0.42 \pm 1.50$ & 0.25 & - \\
\hline & & Yes & 5 & $-1.19 \pm 1.26$ & & \\
\hline & Platelet aggregation & No & 532 & $-0.43 \pm 1.50$ & 0.44 & - \\
\hline & inhibitors & Yes & 21 & $-0.17 \pm 1.53$ & & \\
\hline \multirow{2}{*}{\multicolumn{2}{|c|}{ Pacemaker }} & No & 541 & $-0.42 \pm 1.50$ & 0.65 & - \\
\hline & & Yes & 12 & $-0.61 \pm 1.63$ & & \\
\hline \multirow{2}{*}{\multicolumn{2}{|c|}{ Genetic anomalies }} & No & 449 & $-0.33 \pm 1.47$ & 0.09 & 0.08 \\
\hline & & Yes & 20 & $-0.90 \pm 1.70$ & & \\
\hline
\end{tabular}
capacity; ACE, angiotensin-converting enzyme; ARB, angiotensin II receptor blocker. Values are correlation coefficients ( $r$ ) or means \pm standard deviation (SD). 


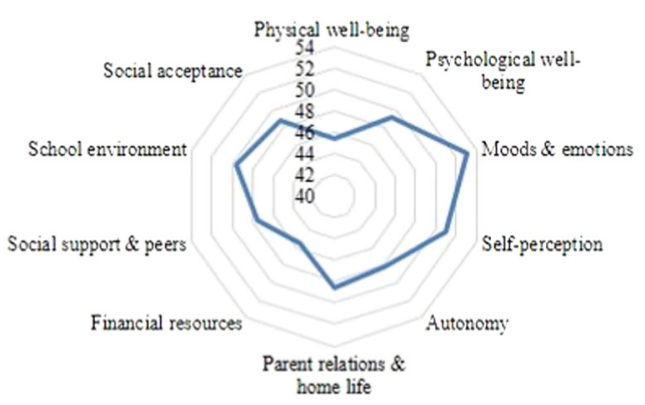

Proxy-reported quality of life scores (Kidscreen 27)

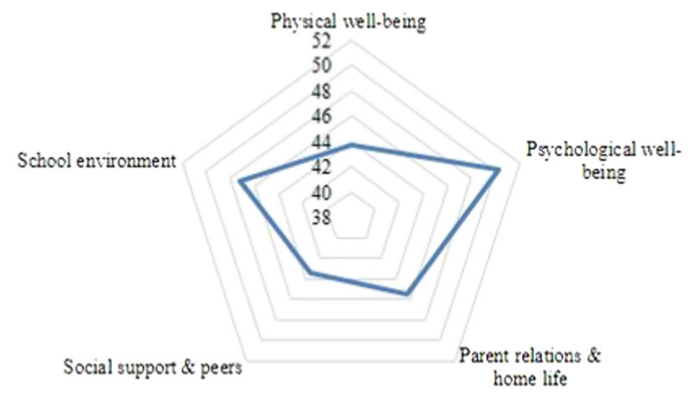

Correlations between spirometry variables and proxy-reported quality of life scores

\begin{tabular}{|l|c|c|c|c|} 
& FVC & FEV1 & FVC/FEV1 ratio & 1 \\
\hline Physical well-being & $-\mathbf{0 . 2 0}$ & $-\mathbf{0 . 1 8}$ & 0.04 & 0.8 \\
\hline Psychological well-being & -0.13 & -0.13 & -0.02 & 0.6 \\
\hline Parent relations \& home life & 0.06 & 0.11 & 0.02 & 0.4 \\
\hline Social support \& peers & 0.009 & 0.02 & 0.01 & 0.2 \\
\hline School environment & -0.08 & -0.08 & 0.03 & 0 \\
& & & & -0.2 \\
& & & -0.4 \\
& & & -0.6 \\
& & & -0.8 \\
\hline
\end{tabular}

Fig. 1. Self-reported (Kidscreen 52) and proxy-reported (Kidscreen 27) quality of life scores in the CHD group and Correlations between spirometry variables and quality of life scores in the CHD group. Legend: correlation matrix between spirometry variables and quality of life scores ( 10 dimensions of the Kidscreen- 52 for the self-reports, and 5 dimensions of the Kidscreen27 for the proxy-reports). Shades of blue indicate increasing positive correlation coefficient; shades of red indicate increasing negative correlation coefficient. Significant coefficients are marked in bold.

The FVC correlated with quality of life scores in the following dimensions: financial resources $(r=0.33, P<0.0001)$ and autonomy $(r=0.20, P=0.01)$ for the self-reports, and the physical well-being $(r=-0.20, P=0.01)$ for the proxy-reports.

The FEV1 correlated with quality of life scores in the following dimensions: financial resources $(r=0.35, P<0.0001)$ and autonomy $(r=0.24, P<0.01)$ for the self-reports, and the physical well-being $(r=-0.18, P=0.03)$ for the proxy-reports.

The FEV1/FVC ratio did not correlate with any quality of life scores. Overall correlations results between spirometry variables and quality of life scores in the CHD group were summarized on Fig. 1.

\section{Discussion}

This multicentre study of a large cohort of 834 children assessed the pulmonary function of 555 children with CHD in comparison with 279 matched healthy controls, and evaluated the relation between lung function and quality of life, in the CHD group.

This study used, for the first time in a paediatric population, the Zscores from the 2012 global lung function initiative to define the pulmonary function in children with CHD, as recommended by the American Thoracic Society and the European Respiratory Society [23,26]. Overall, FVC and FEV1 were significantly lower in children with CHD than in healthy subjects, whereas the FEV1/FVC ratio was normal and similar in both groups. Therefore, children with CHD in this study did not present any obstructive airway disorder, but our results suggest the existence of a restrictive pattern on spirometry. Similar results were reported in the study from Pianosi et al., which included paediatric and adult CHD patients [12]. In our study, the presence of a CHD increased the risk of having an impaired FVC by 6 times, when compared with controls.

In this paediatric cohort, the FVC was predominantly impaired in complex CHD and in patients with a history of one or more cardiac surgery procedures. Similarly, in their adult CHD cohort, AlonsoGonzalez et al. reported that moderate to severe impairment of lung function was related to the complexity of the underlying cardiac defect and a history of thoracic surgery [17]. These authors suggested that thoracic surgery might induce an inflammatory response in the pulmonary vasculature, inducing damage to the alveolar membrane and blood-gas exchange abnormalities. Our results are also in line with the study from Hawkins et al., showing that restrictive lung function was more common in children with CHD after cardiac surgery than in controls or non-operated patients [15]. As in our study, the prevalence of restrictive lung function in children with CHD increased significantly with each additional thoracic surgical procedure.

In our study, a low BMI was associated with an impaired lung function. Children with CHD are at an increased risk for wasting, underweight and stunting [27]. Classically, malnutrition leads to muscle atrophy and restrictive lung function by lack of respiratory muscle strength $[28,29]$. In adult patients with chronic heart failure, respiratory muscle strength is reduced and represents an independent predictor of prognosis [30]. As a result, patients with chronic heart failure present a rapid and shallow ventilation or excessive ventilation during exercise, and, ultimately, exercise intolerance with muscular deconditioning and impaired $\mathrm{VO}_{\max }$ [31]. Similar pathophysiology has been described in the CHD population and cardiac rehabilitation may be a beneficial addition to the current management of children with CHD, potentially reducing long-term morbidity and mortality in adulthood [32,33]. Indeed, in a population of teenagers with a Fontan circulation, a six-week inspiratory muscle-training program was associated with improved inspiratory muscle strength, ventilatory efficiency of exercise, and resting cardiac output [34]. Therefore, active nutritional management and respiratory muscle strength training, added to conventional aerobic training, should be considered in cardiac rehabilitation programs dedicated to the paediatric CHD population. 
The FVC, in this paediatric cohort, was associated with the level of exercise capacity, as assessed by the peak VO2. Currently, most children with CHD have a normal ventilatory anaerobic threshold and therefore are not limited in their submaximal physical performance [35], but their $\mathrm{VO} 2_{\max }$ remains lower than healthy children, with a $\mathrm{VO} 2_{\max }$ decline of $2 \%$ per year [9]. Despite the promotion of physical activity in the current guidelines [36,37], many adolescents and young adults with CHD are trapped in the vicious circle of deconditioning, and, ultimately, exposed to the consequences of a sedentary lifestyle: overweight, high blood pressure, social exclusion, and impaired quality of life [38,39]. Conversely, CHD patients who have been physically active since childhood are less likely to become sedentary adults [40]. The existence of an impaired exercise capacity in patients with CHD classically involves multifactorial mechanisms: hemodynamic changes, chronotropic insufficiency, desaturation, and muscular deconditioning $[10,11]$. Our results suggest that the exercise capacity evaluation in children with CHD should also consider lung function assessment.

In this study, the FVC of children with CHD correlated with their health-related quality of life, especially when reported by the children themselves. Interestingly, this correlation was more predominant in the dimensions related to the child's autonomy (school, peers, finances), than in the physical dimension. Classically, children with CHD are often overprotected by their parents, stigmatized at school and have less autonomy [3]. Many children with CHD suffer from an unpleasant feeling of exercise-induced dyspnoea, and, cumulated with social barriers to physical activity, often remain "on the side-line" at school or in their social life [3]. In the CHD paediatric population, we recently showed that $\mathrm{VO}_{\max }$ was the most correlated CPET variable to quality of life, especially with the physical dimension of the Kidscreen instrument $(r \approx 0.6)$ [8]. Therefore, the present study suggests that the existence of a restrictive spirometry pattern in children with CHD represents an additional factor affecting their quality of life, in the overall spectrum of impaired exercise capacity. Indeed, the feeling of shortness of breath in children with CHD can be related to muscular deconditioning, altered $\mathrm{VO}_{\max }$ and impaired lung function, which together impact their quality of life.

\subsection{Study limitations}

This study was performed in tertiary care centres and may not represent CHD in the general population. The control group was recruited at the hospital and may not be considered as healthy as if they were recruited from the general population. However, this bias seems very limited, considering that children were classified in the control group only after a completely normal check-up, including physical examination, electrocardiogram, and echocardiography. Moreover, the percentage of control children with impaired FVC, FEV1 or FEV1/FVC was of $4 \%$, $4 \%$ and $7 \%$, respectively, using the 5 th centile (Z-score $=-1.64$ ) to define the lower limit of normal. Therefore the control subjects in this study can be considered as healthy children, considering their spirometry results.

Statistical analyses in the three smallest sample size sub-groups should be interpreted with caution (e.g. heterotaxy, complex anomalies of the atrioventricular connections and coronary artery anomalies).

This study suggested the existence of a restrictive pattern with an impaired FVC, from spirometry assessment. The diagnosis of a restrictive lung disease requires the measurement of the total lung capacity with a body plethysmography [41]. Therefore, we plan to perform a study using plethysmography in children with CHD and abnormal spirometry to evaluate the degree of restrictive lung disease in this population.

\section{Conclusion}

In this study, one fifth of children with CHD presented an impaired lung function, with a restrictive spirometry pattern. Indeed, the FVC was associated with the severity of the CHD, the number of thoracic surgery procedures, an impaired exercise capacity, and the existence of a low body mass index, suggesting a lack of respiratory muscle strength, as in adult heart failure.

The lung function in children with CHD correlates with quality of life, highlighting the impact of an unpleasant feeling of dyspnoea on patientrelated outcomes.

Considering that the impairment of lung function is an independent predictor of mortality in adults with CHD, these results suggest that pulmonary function should be monitored early in life, from childhood, in the CHD population.

\section{Declarations of interest}

The authors have no competing interests to declare.

\section{Acknowledgments}

We thank Anne Requirand, Lorraine Saint-Remy, Annie Auer, Cristelle Gerl, and Amandine Marquina (paediatric CPET laboratory technicians). We also thank the children and their families for their participation.

\section{References}

[1] J.I.E. Hoffman, S. Kaplan, The incidence of congenital heart disease, J. Am. Coll. Cardiol. 39 (2002) 1890-1900.

[2] P. Khairy, R. Ionescu-Ittu, A.S. Mackie, et al., Changing mortality in congenital heart disease, J. Am. Coll. Cardiol. 56 (2010) 1149-1157.

[3] P. Amedro, R. Dorka, S. Moniotte, et al., Quality of life of children with congenital heart diseases: a multicenter controlled cross-sectional study, Pediatr. Cardiol. 36 (2015) 1588-1601.

[4] E.R. Hedlund, B. Lundell, L. Villard, et al., Reduced physical exercise and healthrelated quality of life after Fontan palliation, Acta Paediatr. Oslo Nor. 1992105 (2016) 1322-1328.

[5] N. Dempster, C.L. Cua, G. Wernovsky, et al., Children with hypoplastic left heart syndrome have lower quality of life than healthy controls and children with other illnesses, Cardiol. Young 28 (2018) 21-26.

[6] I. Wilmot, C.E. Cephus, A. Cassedy, et al., Health-related quality of life in children with heart failure as perceived by children and parents, Cardiol. Young 26 (2016) $885-893$.

[7] K. Uzark, K. Jones, J. Slusher, et al., Quality of life in children with heart disease as perceived by children and parents, Pediatrics 121 (2008) e1060-e1067.

[8] P. Amedro, M.C. Picot, S. Moniotte, et al., Correlation between cardio-pulmonary exercise test variables and health-related quality of life among children with congenital heart diseases, Int. J. Cardiol. 203 (2016) 1052-1060.

[9] P. Amedro, A. Gavotto, S. Guillaumont, et al., Cardiopulmonary fitness in children with congenital heart diseases versus healthy children, Heart Br. Card. Soc. 104 (12) (2017) 1026-1036.

[10] A. Kempny, K. Dimopoulos, A. Uebing, et al., Reference values for exercise limitations among adults with congenital heart disease. Relation to activities of daily life-single centre experience and review of published data, Eur. Heart J. 33 (2012) 1386-1396.

[11] R. Buys, V. Cornelissen, A.D.B. Van, et al., Measures of exercise capacity in adults with congenital heart disease, Int. J. Cardiol. 153 (2011) 26-30.

[12] P.T. Pianosi, J.N. Johnson, A. Turchetta, et al., Pulmonary function and ventilatory limitation to exercise in congenital heart disease, Congenit. Heart Dis. 4 (2009) $2-11$.

[13] S.A. Rowe, K.G. Zahka, T.A. Manolio, et al., Lung function and pulmonary regurgitation limit exercise capacity in postoperative tetralogy of Fallot, J. Am. Coll. Cardiol. 17 (1991) 461-466.

[14] B. Mazurek, L. Szydlowski, M. Mazurek, et al., Comparison of the degree of exercise tolerance in children after surgical treatment of complex cardiac defects, assessed using ergospirometry and the level of brain natriuretic peptide, Medicine (Baltimore) 95 (2016) e2619.

[15] S.M.M. Hawkins, A.L. Taylor, S.H. Sillau, et al., Restrictive lung function in pediatric patients with structural congenital heart disease, J. Thorac. Cardiovasc. Surg. 148 (2014) 207-211.

[16] H.A. Sadeghi, S.R. Miri, H. Bakhshandeh, et al., Does early tetralogy of Fallot total correction give better final lung volumes? Asian Cardiovasc. Thorac. Ann. 21 (2013) $270-274$.

[17] R. Alonso-Gonzalez, F. Borgia, G.-P. Diller, et al., Abnormal lung function in adults with congenital heart disease: prevalence, relation to cardiac anatomy, and association with survival, Circulation 127 (2013) 882-890.

[18] L. Houyel, B. Khoshnood, R.H. Anderson, et al., Population-based evaluation of a suggested anatomic and clinical classification of congenital heart defects based on the 
International Paediatric and Congenital Cardiac Code, Orphanet. J. Rare Dis. 6 (2011) 64.

[19] C.A. Warnes, R. Liberthson, G.K. Danielson, et al., Task force 1: the changing profile of congenital heart disease in adult life, J. Am. Coll. Cardiol. 37 (2001) 1170-1175.

[20] V. Brusasco, R. Crapo, G. Viegi, et al., Coming together: the ATS/ERS consensus on clinical pulmonary function testing, Eur. Respir. J. 26 (2005) 1-2.

[21] M.R. Miller, J. Hankinson, V. Brusasco, et al., Standardisation of spirometry, Eur. Respir. J. 26 (2005) 319-338.

[22] A. Zapletal, E.K. Motoyama, K.P. Van De Woestijne, et al., Maximum expiratory flowvolume curves and airway conductance in children and adolescents, J. Appl. Physiol. 26 (1969) 308-316.

[23] P.H. Quanjer, S. Stanojevic, T.J. Cole, et al., Multi-ethnic reference values for spirometry for the 3-95-yr age range: the global lung function 2012 equations, Eur. Respir. J. 40 (2012) 1324-1343.

[24] U. Ravens-Sieberer, P. Auquier, M. Erhart, et al., The KIDSCREEN-27 quality of life measure for children and adolescents: psychometric results from a cross-cultural survey in 13 European countries, Qual. Life Res. Int. J. Qual. Life Asp. Treat Care Rehab. 16 (2007) 1347-1356.

[25] U. Ravens-Sieberer, A. Gosch, L. Rajmil, et al., KIDSCREEN-52 quality-of-life measure for children and adolescents, Expert Rev. Pharmacoecon. Outcomes Res. 5 (2005) 353-364.

[26] B.H. Culver, B.L. Graham, A.L. Coates, et al., Recommendations for a standardized pulmonary function report. An official American Thoracic Society technical statement, Am. J. Respir. Crit. Care Med. 196 (2017) 1463-1472.

[27] B. Medoff-Cooper, C. Ravishankar, Nutrition and growth in congenital heart disease: a challenge in children, Curr. Opin. Cardiol. 28 (2013) 122-129.

[28] B. Dureuil, Y. Matuszczak, Alteration in nutritional status and diaphragm muscle function, Reprod. Nutr. Dev. 38 (1998) 175-180.

[29] M.I. Lewis, M.J. Belman, Nutrition and the respiratory muscles, Clin. Chest Med. 9 (1988) 337-348.

[30] F.J. Meyer, M.M. Borst, C. Zugck, et al., Respiratory muscle dysfunction in congestive heart failure: clinical correlation and prognostic significance, Circulation 103 (2001) 2153-2158.

[31] Y. Kasahara, K.P. Izawa, S. Watanabe, et al., The relation of respiratory muscle strength to disease severity and abnormal ventilation during exercise in chronic heart failure patients, Res. Cardiovasc. Med. 4 (2015) e28944.
[32] M. Gomes-Neto, M.B. Saquetto, C.M. da Silva e Silva, et al., Impact of exercise training in aerobic capacity and pulmonary function in children and adolescents after congenital heart disease surgery: a systematic review with meta-analysis, Pediatr. Cardiol. 37 (2016) 217-224.

[33] N. Duppen, T. Takken, M.T.E. Hopman, et al., Systematic review of the effects of physical exercise training programmes in children and young adults with congenital heart disease, Int. J. Cardiol. 168 (2013) 1779-1787.

[34] K. Laohachai, D. Winlaw, H. Selvadurai, et al., Inspiratory muscle training is associated with improved inspiratory muscle strength, resting cardiac output, and the ventilatory efficiency of exercise in patients with a Fontan circulation, J. Am. Heart Assoc. 6 (2017)https://doi.org/10.1161/JAHA.117.005750.

[35] J. Müller, B. Böhm, S. Semsch, et al., Currently, children with congenital heart disease are not limited in their submaximal exercise performance, Eur. J. Cardio-Thorac. Surg. Off. J. Eur. Assoc. Cardio-Thorac. Surg. 43 (2013) 1096-1100.

[36] T. Takken, A. Giardini, T. Reybrouck, et al., Recommendations for physical activity, recreation sport, and exercise training in paediatric patients with congenital heart disease: a report from the Exercise, Basic \& Translational Research Section of the European Association of Cardiovascular Prevention and Rehabilitation, the European Congenital Heart and Lung Exercise Group, and the Association for European Paediatric Cardiology, Eur. J. Prev. Cardiol. 19 (2012) 1034-1065.

[37] P.E. Longmuir, J.A. Brothers, S.D. de Ferranti, et al., Promotion of physical activity for children and adults with congenital heart disease: a scientific statement from the American Heart Association, Circulation 127 (2013) 2147-2159.

[38] C. Karsenty, P. Maury, N. Blot-Souletie, et al., The medical history of adults with complex congenital heart disease affects their social development and professional activity, Arch. Cardiovasc. Dis. 108 (2015) 589-597.

[39] C. Tamayo, C. Manlhiot, K. Patterson, et al., Longitudinal evaluation of the prevalence of overweight/obesity in children with congenital heart disease, Can. J. Cardiol. 31 (2015) $117-123$.

[40] F. Moola, B.W. McCrindle, P.E. Longmuir, Physical activity participation in youth with surgically corrected congenital heart disease: devising guidelines so Johnny can participate, Paediatr. Child Health 14 (2009) 167-170.

[41] J. Wanger, J.L. Clausen, A. Coates, et al., Standardisation of the measurement of lung volumes, Eur. Respir. J. 26 (2005) 511-522. 